\title{
Use of Aerosolized Antifungals for the Prophylaxis Against and Treatment of Invasive Pulmonary Aspergillosis: Climbing it because it is there?
}

\section{Michael E. Klepser*}

Michael E. Klepser, PharmD, Ferris State University College of Pharmacy, Kalamazoo Center for Medical Studies, 1000 Oakland Dr. Kalamazoo, MI 49008, USA

In 1923, English mountaineer George Mallory was asked by a reporter why he wanted to climb Mount Everest. The explorer famously replied, "Because it's there." Mallory's bravado was widely celebrated and people worldwide followed Mallory in his quest to become the first man to reach the summit of Mount Everest. On June 8, 1924 as George Mallory was approaching the summit, an observer watched him disappear into the cloudy veil that shrouded the mountain, never to be seen alive again. What cost George Mallory his life that day in 1924 ? Was it the mountain? Was it lack of equipment and training? Or was it that his judgment became clouded by his desire to reach the summit? Regardless, Mallory lost his life because it was there.

The idea of delivery of an antimicrobial directly to the site of infection has long-intrigued clinicians. This quest to maximize drug exposure at the site of infections whilst minimizing systemic exposure has become quite an adventure. Spawned by the desire to improve therapeutic outcomes among patients with pulmonary infections, some clinicians have advocated the administration of various antimicrobials via inhalation of aerosolized drug solution. For decades this practice continued despite the lack of good evidence to support these practices. This sense of bravado was reminiscent of Mr. Mallory. When one clinician was asked why he was administering the antibiotic by nebulization he calmly and confidently replied, "Because I can." Granted decades' worth of case reports and poorly controlled studies had been published on the topic, the infatuation with aerosolized delivery of antimicrobials seems rather illogical.

What is known about aerosolized delivery of antimicrobials is that just because you can put a drug into a nebulizer does not mean that the medication will be delivered to the site of infection in the lungs or that it will be better tolerated by patients. It has been reported that factors related to the antibiotic, diluent, ambient conditions, nebulizer system, and patient all influence how much drug reaches the distal parts of the lung. The complexity of this process becomes evident when one explores the literature that was used to support the approval of tobramycin solution for inhalation and azetreonam for inhalation solution. [Package inserts] Recognition of the influence of multiple variables on the efficacy and tolerability of these formulations has prompted the manufactures to provide explicit instructions on how to handle the solutions and which nebulizers to use for generation of aerosols.

Aspergillosis is a pathogenically interesting infectious process as it relates to the possible use of targeted antifungal delivery. With few exceptions, the primary mode of acquisition of an Aspergillus spp. is by the inhalation of conidia. Once inhaled, the conidia are deposited in the distal portions of the respiratory tract. Here, the conidia bathe in epithelial lining fluid and may be engulfed by pulmonary macrophages; however, until germination occurs, the pathogen does not invade the host. Hence, conidia and newly germinating moulds should be relatively easy to eradicate since tissue invasion has not yet occurred. Even once tissue invasion occurs during the initial stages of infection, most hyphae remain localized within lung tissue. During this phase of the infection, many hypothesize the pathogen may be more efficiently treated before dissemination occurs.

Another factor that has spurred interest in the use of inhaled antifungals for invasive aspergillosis is that in spite of the availability of newer agents with improved activity against Aspergillus spp., morbidity and mortality associated with infection remain high. Generally, successful outcomes associated with various treatment regimens still are typically less than 55\% [9]. Although several factors may contribute to these poor outcomes, inability to continue primary therapy owing to systemic toxicities and inter-patient pharmacokinetic variability (e.g., time to achieve therapeutic concentrations in the pulmonary tissue, concentration in the pulmonary tissue) are prominent concerns.

For the reasons cited above, aerosolized administration of antifungals for the prophylaxis against and treatment of invasive aspergillosis has widespread appeal. Although several antimicrobials have been studied in vitro and in animal models for these indications, amphotericin $\mathrm{B}$ has been the agent most thoroughly examined $[21,11,1,19]$. Amphotericin B possesses several features that make localized delivery to the lungs attractive. Amphotericin B exhibits rapid, concentration dependent fungicidal activity. Therefore, higher concentrations in the lungs may improve activity. The ability to achieve higher concentrations of amphotericin B in the lungs via traditional intravenous administration is hampered by concerns over drug solubility in aqueous environments and toxicity. Virtually all patients who receive the deoxycholate formulation of amphotericin B will experience some degree of nephrotoxicity. Although the development of nephrotoxicity can be minimized with the administration of lipidbased formulations, patient tolerability and disappointing outcomes are still a concern.

The safety and intrapulmonary distribution characteristics of various formulations of amphotericin B have been studied in various animal models, healthy subjects and patient populations $[20,12,14,17,5,13,7]$. Deoxycholate formulations of amphotericin B have been found to increase the surface tension of the natural surfactant found in the lung which might result in impaired pulmonary function [6,17]. This effect was attributed to the deoxycholate component as pure amphotericin $\mathrm{B}$

*Corresponding author: Michael E. Klepser, PharmD, Ferris State University College of Pharmacy, Kalamazoo Center for Medical Studies, 1000 Oakland Dr. Kalamazoo, MI 49008, USA, E-mail: klepserm@ferris.edu

Received December 01, 2011; Accepted December 07, 2011; Published December 09, 2011

Citation: Klepser ME (2011) Use of Aerosolized Antifungals for the Prophylaxis Against and Treatment of Invasive Pulmonary Aspergillosis: Climbing it because it is there? Pharm Anal Acta S1:e001. doi:10.4172/2153-2435.S1-e001

Copyright: (C) 2011 Klepser ME. This is an open-access article distributed unde the terms of the Creative Commons Attribution License, which permits unrestricted use, distribution, and reproduction in any medium, provided the original author and source are credited. 
and lipid-based formulations did not exhibit this effect [17]. Regarding affect on pulmonary function following inhalation of amphotericin $B$, the data remain mixed; however, the most common manifestations include cough, shortness of breath and wheezing [15,18,2,4,10,8,3,16]. Given these safety and tolerability data, it seems reasonable that if an amphotericin B formulation is to be considered for aerosolization that a lipid-based formulation be used preferentially over deoxycholate.

From a pharmacokinetic perspective, inhalation of amphotericin B results in rapid attainment of therapeutic concentrations in epithelial lining fluid which remain above $1 \mu \mathrm{g} / \mathrm{ml}$ for more than 7 days following inhalation [12]. This characteristic is in contrast to data observed following intravenous administration which demonstrate delayed distribution to the pulmonary tissues and appreciably lower drug concentrations [14].

Currently, limited data exist regarding the use of aerosolized amphotericin B for the treatment of aspergillosis. In the setting of established infection, uncertainty about airway blockage, necrosis, and dissemination of infection make advocating aerosolized amphotericin $\mathrm{B}$ as the sole means of treatment foolish. However, because this means of drug delivery provides therapeutic drug concentrations to the lungs within minutes it may be reasonable to explore short-term use of inhaled amphotericin B with a concurrently administered intravenous agent. Unfortunately, clinical data supporting this approach are nonexistent.

With respect to the use of inhaled amphotericin B for prophylaxis against invasive pulmonary aspergillosis, the two most cited studies are those conducted by Schwartz and Rijnders [16,18]. In the study conducted by Schwartz and colleagues, 382 patients with prolonged neutropenia were randomized to receive either inhaled amphotericin B deoxycholate (10 $\mathrm{mg}$ twice daily) or no inhalation [18]. The investigators failed to demonstrate any differences with respect to proven, probable, or possible Aspergillus infections or overall mortality. In contrast, Rijnders and colleagues randomized a total of 271 patients with prolonged neutropenia to receive either aerosolized liposomal amphotericin B (15 mg over 30 minutes on two consecutive days per week for a maximum of 6 weeks) or placebo. According to the intention-to-treat and on-treatment analyses, inhaled liposomal amphotericin $\mathrm{B}$ reduced the incidence of invasive pulmonary aspergillosis by approximately $10 \%$ compared to placebo $(\mathrm{p}<0.05)$. However, no difference was noted between groups with respect to survival.

So if these studies provide conflicting results, can we draw any meaningful guidance from the data? First, one must recognize that these studies are by no means comparable. Owing to the distance between study periods $[2,16]$ prevailing medical and infection control practices likely differed significantly. Also, diagnostic tools and definitions of infection differed appreciably between the studies. Then there are the differences in amphotericin B formulations, administration schedules, and nebulizers. We might as well try to compare the musical merits of Mozart to Van Halen. However, in spite of this it is fair to conclude that liposomal amphotericin B administered via inhalation at a dose of 15 mg over 30 minutes on two consecutive days per week for a maximum of 6 weeks by an adaptive aerosol delivery system (Halolite ADD or ProDose ADD; Romedic/Medic-Aid) is more effective in preventing invasive pulmonary aspergillosis than placebo. Great, case closed. Hold on a second. What if you do not have access to one of these nebulizers? Why only treat for two consecutive days per week? Do the days on which patients receive inhalations have to be the same days each week? What do you do if a patient misses a dose? And then the $\$ 1,000,000$ question is this as good as prophylaxis with posaconazole or voriconazole?

Let me try to summarize. Can we safely administer amphotericin B to patients? Yes. Does it matter what formulation of amphotericin B we use? Yes. Deoxycholate formulations appear to be less well tolerated. Does it matter which regimen and nebulizer we select? May be. No good comparative data are available. Can we use this means of drug delivery to treat established Aspergillus infections? No. Good data are currently lacking. Can we use this means of drug delivery for prophylaxis against Aspergillus spp? Yes. Administration of liposomal amphotericin B is more effective than placebo. Is this means of prophylaxis as effective as oral administration of posaconazole or voriconazole? No idea. There are no comparative head-to-head data.

So a word of caution from the specter of mountaineer George Mallory. Just because a mountain is there does not mean that it is the best idea to climb it. Similarly just because we can administer antifungals by aerosolization does not mean that we should.

\section{References}

1. Alvarez CA, Wiederhold NP, McConville JT, Peters JI, Najvar LK, et al. (2007) Aerosolized nanostructured itraconazole as prophylaxis against invasive pulmonary aspergillosis. J Infect 55: 68-74.

2. Behre GF, Schwartz S, Lenz K, Ludwig WD, Wandt H, et al. (1995) Aeroso amphotericin $\mathrm{B}$ inhalations for prevention of invasive pulmonary aspergillosis in neutropenic cancer patients. Ann Hematol 71: 287-291.

3. Dubois J, Bartter T, Gryn J, Pratter MR (1995) The physiologic effects of inhaled amphotericin B. Chest 108:750-753.

4. Erjavec Z, Woolthuis GM, de Vries-Hospers HG, Sluiter WJ, Daenen SM, et al. (1997) Tolerance and efficacy of Amphotericin B inhalations for prevention of invasive pulmonary aspergillosis in haematological patients. Eur $\mathrm{J}$ Clin Microbiol Infect Dis 16: 364-368.

5. Gavaldà J, Martín MT, López P, Gomis X, Ramírez JL, et al. (2005) Efficacy of nebulized liposomal amphotericin B in treatment of experimental pulmonary aspergillosis. Antimicrob Agents Chemother 49: 3028-3030.

6. Griese M, Schams A, Lohmeier KP (1998) Amphotericin B and pulmonary surfactant. Eur J Med Res 3: 383-386.

7. Groll AH, Lyman CA, Petraitis V, Petraitiene R, Armstrong D, et al. (2006) Compartmentalized intrapulmonary pharmacokinetics of amphotericin $\mathrm{B}$ and its lipid formulations. Antimicrob Agents Chemother 50: 3418-3423.

8. Gryn J, Goldberg J, Johnson E, Siegel J, Inzerillo J (1993) The toxicity of daily inhaled amphotericin B. Am J Clin Oncol. 16: 43-46.

9. Herbrecht R, Denning DW, Patterson TF, Bennett JE, Greene RE, et al. (2002) Invasive Fungal Infections Group of the European Organisation for Research and Treatment of Cancer and the Global Aspergillus Study Group. Voriconazole versus amphotericin B for primary therapy of invasive aspergillosis. $\mathrm{N}$ Engl J 347: 408-415.

10. Hertenstein B, Kern WV, Schmeiser T, Stefanic M, Bunjes D, et al. (1994) Low incidence of invasive fungal infections after bone marrow transplantation in patients receiving amphotericin B inhalations during neutropenia. Ann Hematol 68: $21-26$

11. Hoeben BJ, Burgess DS, McConville JT, Najvar LK, Talbert RL, et al. (2006) In vivo efficacy of aerosolized nanostructured itraconazole formulations for prevention of invasive pulmonary aspergillosis. Antimicrob Agents Chemother 50: 1552-1554.

12. Husain S, Capitano B, Corcoran T, Studer SM, Crespo M, et al. (2010) Intrapulmonary disposition of amphotericin B after aerosolized delivery of 
Citation: Klepser ME (2011) Use of Aerosolized Antifungals for the Prophylaxis Against and Treatment of Invasive Pulmonary Aspergillosis: Climbing it because it is there? Pharm Anal Acta S1:e001. doi:10.4172/2153-2435.S1-e001

Page 3 of 3

amphotericin $B$ lipid complex (Abelcet; $A B L C)$ in lung transplant recipients. Transplantation 90: 1215-1219.

13. Knechtel SA, Klepser ME (2007) Safety of aerosolized amphotericin B. Expert Opin Drug Saf 6: 523-532.

14. Koizumi T, Kubo K, Kaneki T, Hanaoka M, Hayano T, et al. (1998) Pharmacokinetic evaluation of amphotericin B in lung tissue: lung lymph distribution after intravenous injection and airspace distribution after aerosolization and inhalation of amphotericin B. Antimicrob Agents Chemother 42: $1597-1600$.

15. Marra F, Partovi N, Wasan KM, Kwong EH, Ensom MH, et al. (2002) Amphotericin $\mathrm{B}$ disposition after aerosol inhalation in lung transplant recipients. Ann Pharmacother 36: 46-51.

16. Rijnders BJ, Cornelissen JJ, Slobbe L, Becker MJ, Doorduijn JK, et al. (2008) Aerosolized liposomal amphotericin $\mathrm{B}$ for the prevention of invasive pulmonary aspergillosis during prolonged neutropenia: a randomized, placebo-controlled trial. Clin Infect Dis 46: 1401-1408.

17. Ruijgrok EJ, Vulto AG, Van Etten EW (2001) Efficacy of aerosolized amphotericin B desoxycholate and liposomal amphotericin B in the treatment of invasive pulmonary aspergillosis in severely immunocompromised rats. J
Antimicrob Chemother 48:89-95.

18. Schwartz S, Behre G, Heinemann V, Wandt H, Schilling E, et al. (1999) Aerosolized amphotericin B inhalations as prophylaxis of invasive aspergillus infections during prolonged neutropenia: results of a prospective randomized multicenter trial. Blood 93: 3654-3661.

19. Takazono T, Izumikawa K, Mihara T, Kosai K, Saijo T, et al. (2009) Efficacy of combination antifungal therapy with intraperitoneally administered micafungin and aerosolized liposomal amphotericin B against murine invasive pulmonary aspergillosis. Antimicrob Agents Chemother. 53: 3508-3510.

20. Vyas SP, Quraishi S, Gupta S, Jaganathan KS (2005) Aerosolized liposomebased delivery of amphotericin B to alveolar macrophages. Int J Pharm 296 12-25.

21. Wong-Beringer A, Lambros MP, Beringer PM, Johnson DL (2005) Suitability of caspofungin for aerosol delivery: physicochemical profiling and nebulizer choice. Chest 128: 3711-3716.

22. Cayston package insert

23. TOBI package insert 